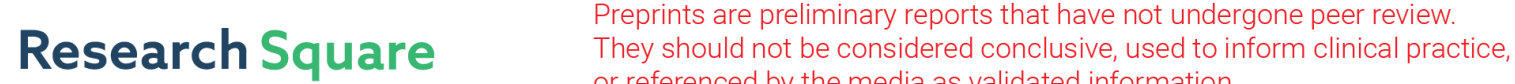 \\ or referenced by the media as validated information. \\ Risk Factors Associated With Mortality in Hypersensitivity Pneumonitis: A Meta-analysis
}

\section{Sanjukta Dasgupta}

Indian Institute of Technology Kharagpur

Anindita Bhattacharya

Indian Institute of Technology Kharagpur

\section{Sushmita Roy Chowdhury}

Fortis

Koel Chaudhury ( $\nabla$ koeliitkgp@gmail.com )

Indian Institute of Technology Kharagpur https://orcid.org/0000-0002-9390-1179

\section{Research Article}

Keywords: hazard ratio, hypersensitivity pneumonitis, meta-analysis, mortality

Posted Date: October 20th, 2021

DOI: https://doi.org/10.21203/rs.3.rs-951727/v1

License: (1) (1) This work is licensed under a Creative Commons Attribution 4.0 International License. Read Full License 


\section{Abstract}

Purpose: Hypersensitivity pneumonitis (HP), an immune-mediated form of diffuse parenchymal lung disease (DPLD), is triggered by inhalation of a wide variety of allergens in susceptible individuals. Several studies suggest that the death rate associated with this disease has increased significantly in recent years. This meta-analysis investigates the significant clinico-radiological characteristics which may be appraised as potential risk factors associated with disease mortality.

Methods: Extensive literature search was conducted for original articles published between January 2009 and April 2021 through PubMed, Google Scholar, EMBASE, and Cochrane Library using the keywords: "hypersensitivity pneumonitis", "hazard ratio" and "mortality".

Results: A total of 21 independent studies related to mortality of HP subjects could be identified. The combined results of univariate and multivariate analysis suggest that older age [univariate odds ratio (OR) 1.038 (1.028-1.048); multivariate OR 1.036, (1.025-1.046)], male subjects [univariate OR 1.508, (1.240-1.834); multivariate OR 1.396, (1.004-1.943)], honeycombing [univariate OR 1.086 (1.065-1.108); multivariate OR 1.121 (1.070-1.175)] and traction bronchiectasis [univariate OR 1.141 (1.092-1.192); multivariate OR 1.107 (1.048-1.169)] are significantly associated with mortality risk of HP subjects. Further, forced vital capacity (FVC), diffusing capacity for carbon monoxide (DLco), ground glass opacity (GGO) and mosaic attenuation were associated with lower risk of all-cause mortality. Although smoking status correlated with mortality risk in these patients, the findings appeared to be insignificant.

Conclusion: Individual male subjects with older age and presence of extensive fibrosis, i.e., honeycombing and traction bronchiectasis experience an increased mortality risk.

\section{Introduction}

Hypersensitivity pneumonitis (HP), an immune-mediated form of diffuse parenchymal lung disease (DPLD), is triggered by inhalation of a wide variety of allergens in susceptible individuals [1]. The prevalence of HP differs significantly among and even within countries, due to factors such as antigens distribution, geographical location, culture, and climate [2]. An European and a Danish study report that HP accounts for $4-13 \%$ and $7 \%$ of all DPLD cases, respectively [3, 4]. HP comprises of $47.8 \%$ of the total number of DPLD cases among Indian population [5].

Several studies suggest that the rate of death associated with this granulomatous disease has increased significantly in recent years [6]. An earlier United States (US) population-based mortality study reported a significant increase in death rate from 0.09 to 0.29 per million between 1980 and 2002 [7]. A recent study, again on the US population, reports that HP-related mortality rate increased considerably from 0.12 per million to 0.68 per million between 1988 and 2016 [8]. Most of the mortality associated data are from patients of Western countries; data from Asian patient population remains scarce. Only a limited number of reports exist on mortality assessment of HP in Asian population, with Japan and China reporting a median survival time of 74.5 months for chronic HP and 83 months for HP, respectively $[9,10]$. Despite the 
high incidence rate, not all patients diagnosed with HP die or need a lung transplant. It is likely that some key factors increase the risk of death or cause critical medical complications in these patients. Identification of such modifiable risk factors associated with mortality in HP patients is, therefore, wellrealized.

In addition to radiological factors, population-based studies suggest involvement of other clinical factors that have a direct influence on mortality of HP patients [11]. Meta-analysis of risk factors for other DPLD subtypes, such as idiopathic pulmonary fibrosis (IPF) and sarcoidosis are documented [12]. However, possibly due to inconsistencies and paucity of evidence, meta-analysis of global risk factors in HP is yet to be reported. Herein, we provide a systematic review and meta-analysis to sharp focus on the significant clinico-radiological characteristics which may be appraised as potential risk factors associated with mortality in HP patients.

\section{Methods}

\section{Literature search}

Extensive literature search was conducted by two independent investigators (SDG and $A B$ ) for original articles published between $1^{\text {st }}$ January 2009 and $30^{\text {th }}$ April 2021. Both authors searched through PubMed, Google Scholar, EMBASE, and Cochrane Library using the keywords: "hypersensitivity pneumonitis", "hazard ratio" and "mortality". In addition, references of relevant research papers were manually screened for additional eligible articles. Finally, inconsistencies associated with the extracted data were discussed with the third and fourth author/reviewer and suitably addressed. The search flow diagram of this meta-analysis is demonstrated in Fig. 1.

\section{Study selection}

The present review includes literature fulfilling the following criteria: (a) full-text access of articles (b) information presented in English (c) peer-reviewed accepted/published articles (d) literature published on and after $1^{\text {st }}$ January 2009 (e) multiple factors available for the survival of HP. Exclusion criteria were as follows: (a) case reports (b) letters to the editor (c) clinical commentaries (d) narrative reviews and (v) case series.

\section{Data extraction}

Two reviewers extracted information from all original articles selected for this meta-analysis. The extracted information included: (1) authors' names (2) publication year (3) sample size (4) country and (5) the diagnostic criteria for HP. The present manuscript is prepared according to the Preferred Reporting Items for Systematic Reviews and Meta-Analyses (PRISMA) guidelines [13].

\section{Statistical analysis}


The strength of association between predefined outcomes and potential factors was determined using odds ratios (OR). Ten factors including 3 demographics (age, sex, smoking status), forced vital capacity (FVC), diffusing capacity for carbon monoxide (DLCO) and 5 radiological [ground glass opacity (GGO), mosaic attenuation, reticulation, honeycombing and traction bronchiectasis] parameters were considered to be the probable risk factors for the mortality of HP patients and heterogeneity calculated for each parameter. The effect size was considered to be the overall OR and reported with a 95\% confidence interval. Heterogeneity was assessed for univariate and multivariate data by Cochrane's $Q$ statistics. The $I^{2}$ value in the forest plot, calculated using STATA software 15.0 (StataCorp, TX, USA), reflects statistical heterogeneity between studies included in the meta-analysis. It determines the significance of the heterogeneity test and is sub-divided into four categories, i.e., 1 . not important $(0 \%-30 \%), 2$. moderate important $(30 \%-50 \%)$, 3. substantial important $(50 \%-70 \%)$ and 4 . considerable important $(70 \%-100 \%)$. A funnel plot was generated to demonstrate publication bias of the covariates (log OR vs standard error of $\log \mathrm{OR})$.

\section{Results}

\section{Overview of the included studies}

Data of 3077 HP patients from 21 independent studies $[10,14,15,16,17,18,19,20,21,22,23,24,25,26,27,28,29,30,31,32,33]$ are extracted and included in the present meta-analysis. For an isolated study, the highest sample size was found to be 753 [28] while the lowest number corresponded to 23 cases of HP [31]. The characteristics of the studies included are summarized in Table 1. Majority of these studies were conducted in US (8/21), followed by United Kingdom (UK) $(4 / 21)$ and Japan (3/21). The remaining six studies were conducted in South Korea, Brazil, Germany, Spain, Denmark and China.

\section{Statistical analysis}

Based on all studies included, a total of 10 potential risk factors for all-cause mortality in HP patients could be identified. The effects of these potential risk factors, including age, sex, smoking status, FVC, $\mathrm{DL}_{\mathrm{CO}}$, honeycombing, mosaic attenuation, reticulation, $\mathrm{GGO}$ and traction bronchiectasis are explored using univariate analysis. We found only 1 study reporting multivariate hazard ratio for reticulation [18]; hence this factor was excluded and the other 9 potential risk factors considered for multivariate analysis.

\section{Univariate analysis}

Univariate analysis identified a total of 6 potential risk factors which were statistically significant for pooled data in meta-analysis. These potential risk factors included older age [overall OR 1.038 (1.0281.048); $I^{2}: 40.8 \%$, p value 0.077 ], male subjects [overall OR 1.508 (1.240-1.834); $I^{2}: 32.4 \%, p$ value 0.180 ], honeycombing [overall OR 1.086 (1.065-1.108); $I^{2}: 86.5 \%$, p value $<0.0001$ ], mosaic attenuation [overall OR 1.016 (1.000-1.032); I': 72.3\%, p value 0.001], reticulation [overall OR 1.021 (1.014-1.029); I2: 95.0\%, p 
value $<0.0001$ ], and traction bronchiectasis [overall OR 1.141 (1.092- 1.192); $\left.\right|^{2}: 88.4 \%, p$ value $<0.0001$ ]. Further FVC, DLCo and GGO were associated with lower risk of all-cause mortality (Fig. 2 and 3). Although smoking status could be correlated with mortality risk in these patients, the findings were not significant (Table S1).

\section{Multivariate analysis and identification of risk factors}

Multivariate analysis indicated significant association between 4 cofactors and mortality of HP subjects. These potential risk factors emerged to be age [overall OR 1.036 (1.025-1.046); $\left.\right|^{2}$ : 58.0\%; $p$ value 0.011], sex (male) [overall OR 1.396 (1.004-1.943); $I^{2}: 0.0 \%$; $p$ value 0.779 ], honeycombing [overall OR 1.121 $(1.070-1.175) ; I^{2}: 89.4 \% ; p$ value $<0.0001$ ] and traction bronchiectasis [overall OR 1.107 (1.048-1.169); $I^{2}$ : 83.3\%; $p$ value 0.003 ] (Fig. 4 and 5). Multivariate analysis revealed mosaic pattern is not associated with mortality risk. The association of smoking status, FVC, DLco and GGO with disease mortality shows similar trend as univariate result (Table S2).

The combined results of univariate and multivariate analysis suggest that patients with advanced age, male subjects and radiological features including honeycombing and traction bronchiectasis are significantly associated with the mortality risk. However, heterogeneity was high regarding most of the outcomes. The funnel plots that were produced to assess publication bias are shown in Fig. S1.

\section{Discussion}

The mortality rate of HP has increased rapidly in the last few decades. Assessment of association between various risk factors and mortality of patients with HP has attracted considerable attention of clinicians from various countries. This is the first attempt to ascertain clinical mortality predictors of HP by meta-analysis. In this systematic review and meta-analysis, we identified 21 studies describing potential risk factors that could be accountable for the mortality of patients with HP.

We observed a higher mortality risk in elderly participants. This is not surprising since advanced age is a well-known risk factor associated with poor prognosis in various DPLD subtypes. Moreover, various comorbidities develop at this stage [34,35]. Also, a growing body of evidence suggests that male HP patients have poor chances of survival [36], which is in agreement with our observations. Clarson and coworkers have shown that male DPLD patients are at a higher risk of developing ischemic heart disease and myocardial infarction, which might influence survival of these subjects [37].

Tobacco smoke is reported to cause damage to the alveolar epithelium and leads to poor prognosis [38]. Interestingly, we observed no significant association between smoking status and disease mortality. Our findings are in accordance with previous studies $[39,40]$. The presence of GGO, mosaic attenuation, lower FVC and DLco did not appear to increase mortality risk in HP subjects. Earlier studies also demonstrate a similar trend, thereby supporting our findings [29]. 
The presence of honeycombing and traction bronchiectasis pattern emerges to be the radiological predictor of mortality for patients with HP. Walsh et al., over nearly a 7-year period, studied the individual high-resolution computed tomography (HRCT) patterns and physiologic indices of patients reporting to a UK-based hospital and diagnosed with chronic HP. The authors found the presence of extensive traction bronchiectasis and honeycombing to strongly associate with disease mortality in chronic HP patients [32]. In another study, Mooney et al. have shown that a greater extent of honeycombing, reticular and traction bronchiectasis is associated with shortened life span in patients with HP [25]. This is in agreement with the findings of Jacob et al., where honeycombing, reticulation and traction bronchiectasis are suggested to be strong predictors of mortality in HP patients [20, 21]. In a recent study, Salisbury et al. have compared the survival time and pulmonary function changes of patients with HP and IPF by radiologic phenotype. HP patients with non-honeycomb fibrosis could be associated with longer survival period than IPF cases. Furthermore, HP and IPF subjects with honeycombing exhibited poor survival and significant decline in predicted FVC\% [29]. In another very interesting study conducted over a 15-year period at the Tokyo Medical and Dental University Hospital, Tateishi et al. defined the HRCT features of acute, recurrent, and insidious cases of 112 bird fancier's lung at the time of initial diagnosis and assessed the HRCT changes over the follow-up period. The authors observed that GGO and centrilobular nodules were predominantly present in acute and recurrent HP, whereas honeycombing was the most prominent feature in insidious and chronic HP. The authors also suggest that patients with the presence of radiographic honeycombing pattern with airspace consolidation are associated with a decreased survival rate [30].

In another population-based single-centric study in China, Wang et al. explored the incidence, clinical characteristics and outcome of 101 patients with HP. Interestingly, in contrast to our analysis, the group found unidentified exposure and low baseline total lung capacity predicted percentage to be the independent risk factors as survival predictors in all subjects. Fibrosis on chest HRCT as a clinical variable was not observed to be statistically significant [10]. Two additional studies are reported where the findings are contrary to our analysis. First, Hanak et al. have investigated the association between survival clinical features including HRCT patterns and spirometric values of 69 patients with subacute or chronic HP. It is suggested that the presence of fibrosis on HRCT images and pulmonary function impairment is associated with reduced survival and an indicator of disease prognosis. However, honeycombing independently could not be significantly correlated with mortality [41]. Second, Sahin and colleagues have retrospectively compared HRCT features of HP patients suggestive of fibrosis with histologic fibrosis score. They concluded that though HRCT findings consisting of extensive reticular pattern, traction bronchiectasis and honeycombing seem to be closely related to the presence of fibrosis in chronic HP; it is the presence of histologic fibrosis and not the CT characteristics which significantly relate to decreased survival [42].

The present study has several limitations that should be acknowledged. First, all studies included are retrospective in nature. Second, subgroup analyses could not be performed due to limited sample size for all the studies. Third, individual observations are clinically different in terms of age, sex, ethnicity, disease severity and diagnostic procedures, which may have contributed to significant heterogeneity in the 
present analysis. Nonetheless, well-defined data extraction, literature search, and quality assessment does strengthen our observations.

\section{Conclusion}

A number of clinical traits such as age, sex, smoking status, DLCO, FVC, radiological features including GGO, mosaic attenuation, reticulation, honeycombing and traction bronchiectasis of patients with HP are analyzed to identify the major risk factors contributing to disease mortality. Age, male subjects, honeycombing and traction bronchiectasis emerged to be the significant risk factors. Multicentric observational and interventional studies are suggested to validate these findings. Also, it is desirable to explore the association of the identified risk factors with disease progression.

\section{Abbreviations}

DLco: Diffusing capacity for carbon monoxide

DPLD: Diffuse parenchymal lung disease

FVC: Forced vital capacity

GGO: Ground glass opacity

HP: Hypersensitivity pneumonitis

HRCT: High-resolution computed tomography

IPF: Idiopathic pulmonary fibrosis

OR: Odds ratio

US: United states

\section{Declarations}

\section{Funding}

Not applicable

Conflicts of interest

None

\section{Availability of data and material}

Not applicable 


\section{Code availability}

Not applicable

\section{Authors' contributions}

S. D. had full access to all of the data in the study and takes responsibility for the integrity and accuracy of the data. S.D. and A.B. conducted the literature search, extracted the results, performed the metaanalyses; and drafted the manuscript. S.R.C and K.C revised the manuscript.

\section{Ethics approval}

No ethical approval was necessary for the present study.

\section{Consent to participate}

Not applicable

\section{Consent for publication}

Not applicable

\section{Acknowledgements}

S.D. and A.B. acknowledge the Ministry of Human Resource and Development, India and Indian Institute of Technology Kharagpur for research fellowship.

\section{References}

1. Raghu G, Remy-Jardin M, Ryerson CJ et al (2020) Diagnosis of hypersensitivity pneumonitis in adults: An official ATS/JRS/ALAT clinical practice guideline. Am J Respir Crit Care Med 202:e36e69. https://doi.org/10.1164/rccm.202005-2032ST

2. Terho $E$, Heinonen O, Lammi S, Laukkanen V (1987) Incidence of clinically confirmed farmer's lung in Finland and its relation to meteorological factors. Eur J Respir Dis Suppl 152:47-56

3. Thomeer MJ, Costabel U, Rizzato G et al (2001) Comparison of registries of interstitial lung diseases in three European countries. Eur Respir J 18:114s-118s

4. Hyldgaard C, Hilberg O, Muller A, Bendstrup E (2014) A cohort study of interstitial lung diseases in central Denmark. Respir Med 108:793-799. https://doi.org/10.1016/j.rmed.2013.09.002

5. Singh S, Collins BF, Sharma BB et al (2017) Interstitial lung disease in India results of a prospective registry. Am J Respir Crit Care Med 195:801-813. https://doi.org/10.1164/rccm.201607-14840C

6. Park JE, Kim YS, Kang MJ et al (2018) Prevalence, incidence, and mortality of sarcoidosis in Korea, 2003-2015: A nationwide population-based study. Respir Med 144S:S28-S34. https://doi.org/10.1016/j.rmed.2018.03.028 
7. Bang KM, Weissman DN, Pinheiro GA et al (2006) Twenty-three years of hypersensitivity pneumonitis mortality surveillance in the United States. Am J Ind Med 49:997-1004. https://doi.org/10.1002/ajim.20405

8. Fernández Pérez ER, Sprunger DB, Ratanawatkul P et al (2019) Increasing hypersensitivity pneumonitis-related mortality in the United States from 1988 to 2016. Am J Respir Crit Care Med 199:1284-1287

9. Okamoto T, Miyazaki Y, Ogura T et al (2013) A nationwide epidemiological survey of chronic hypersensitivity pneumonitis in Japan. Respir Investig 51:191-199. https://doi.org/10.1016/j.resinv.2013.03.004

10. Wang LJ, Cai HR, Xiao YL et al (2019) Clinical characteristics and outcomes of hypersensitivity pneumonitis: A population-based study in China. Chin Med J (Engl) 132:1283-1292. https://doi.org/10.1097/CM9.0000000000000256

11. Mohamed NR, Ghazawy ER, Saeed ZH (2020) Factors influencing the clinical presentation of hypersensitivity pneumonitis in pigeon breeders in Minia governorate: an Egyptian experience. Egypt J Bronchol 14:1-5

12. Brown SAW, Dobelle M, Padilla M et al (2019) Idiopathic Pulmonary Fibrosis and Lung Cancer A Systematic Review and Meta-analysis. Ann Am Thorac Soc 16:1041-1051. https://doi.org/10.1513/AnnalsATS.201807-4810C

13. Liberati A, Altman DG, Tetzlaff J et al (2009) The PRISMA statement for reporting systematic reviews and meta-analyses of studies that evaluate health care interventions: explanation and elaboration. $J$ Clin Epidemiol 62:e1-e34. https://doi.org/10.1016/j.jclinepi.2009.06.006

14. Adegunsoye A, Oldham JM, Demchuk C et al (2016) Predictors of survival in coexistent hypersensitivity pneumonitis with autoimmune features. Respir Med 114:53-60. https://doi.org/10.1016/j.rmed.2016.03.012

15. Adegunsoye A, Oldham JM, Bellam SK et al (2019) Computed tomography honeycombing identifies a progressive fibrotic phenotype with increased mortality across diverse interstitial lung diseases. Ann Am Thorac Soc 16:580-588. https://doi.org/10.1513/AnnalsATS.201807-4430C

16. Choe J, Chae EJ, Kim YJ et al (2021) Serial changes of CT findings in patients with chronic hypersensitivity pneumonitis: imaging trajectories and predictors of fibrotic progression and acute exacerbation. Eur Radiol 31:3993-4003. https://doi.org/10.1007/s00330-020-07469-2

17. Chung JH, Zhan X, Cao M et al (2017) Presence of air trapping and mosaic attenuation on chest computed tomography predicts survival in chronic hypersensitivity pneumonitis. Ann Am Thorac Soc 14:1533-1538. https://doi.org/10.1513/AnnalsATS.201701-0350C

18. Chung JH, Montner SM, Adegunsoye A et al (2017) CT findings associated with survival in chronic hypersensitivity pneumonitis. Eur Radiol 27:5127-5135. https://doi.org/10.1007/s00330-017-4936-3

19. Pérez ERF, Swigris JJ, Forssén AV et al (2013) Identifying an inciting antigen is associated with improved survival in patients with chronic hypersensitivity pneumonitis. Chest 144:1644-1651. https://doi.org/10.1378/chest.12-2685 
20. Jacob J, Bartholmai BJ, Egashira R et al (2017) Chronic hypersensitivity pneumonitis: Identification of key prognostic determinants using automated CT analysis. BMC Pulm Med 17:1-12. https://doi.org/10.1186/s12890-017-0418-2

21. Jacob J, Bartholmai BJ, Rajagopalan S et al (2017) Automated computer-based CT stratification as a predictor of outcome in hypersensitivity pneumonitis. Eur Radiol 27:3635-3646. https://doi.org/10.1007/s00330-016-4697-4

22. Jacob J, Odink A, Brun AL et al (2018) Functional associations of pleuroparenchymal fibroelastosis and emphysema with hypersensitivity pneumonitis. Respir Med 138:95-101. https://doi.org/10.1016/j.rmed.2018.03.031

23. Lima MS, Coletta ENAM, Ferreira RG et al (2009) Subacute and chronic hypersensitivity pneumonitis: Histopathological patterns and survival. Respir Med 103:508-515. https://doi.org/10.1016/j.rmed.2008.12.016

24. Long $X, \mathrm{He} X$, Ohshimo $S$ et al (2017) Serum YKL-40 as predictor of outcome in hypersensitivity pneumonitis. Eur Respir J 49:1501924. https://doi.org/10.1183/13993003.01924-2015

25. Mooney JJ, Elicker BM, Urbania TH et al (2013) Radiographic fibrosis score predicts survival in hypersensitivity pneumonitis. Chest 144:586-592. https://doi.org/10.1378/chest.12-2623

26. Nukui Y, Miyazaki Y, Masuo M et al (2019) Periostin as a predictor of prognosis in chronic bird-related hypersensitivity pneumonitis. Allergol Int 68:363-369. https://doi.org/10.1016/j.alit.2019.02.007

27. Ojanguren I, Morell F, Ramón MA et al (2019) Long-term outcomes in chronic hypersensitivity pneumonitis. Allergy Eur J Allergy Clin Immunol 74:944-952. https://doi.org/10.1111/all.13692

28. Rittig AH, Hilberg O, Ibsen R, Løkke A (2019) Incidence, comorbidity and survival rate of hypersensitivity pneumonitis: a national population-based study. ERJ Open Res 5:00259-02018. https://doi.org/10.1183/23120541.00259-2018

29. Salisbury ML, Gu T, Murray S et al (2019) Hypersensitivity Pneumonitis: Radiologic Phenotypes Are Associated With Distinct Survival Time and Pulmonary Function Trajectory. Chest 155:699-711. https://doi.org/10.1016/j.chest.2018.08.1076

30. Tateishi T, Ohtani Y, Takemura T et al (2011) Serial high-resolution computed tomography findings of acute and chronic hypersensitivity pneumonitis induced by avian antigen. J Comput Assist Tomogr 35:272-279. https://doi.org/10.1097/RCT.0b013e318209c5a6

31. Tsutsui T, Miyazaki Y, Kuramochi J et al (2015) The amount of avian antigen in household dust predicts the prognosis of chronic bird-related hypersensitivity pneumonitis. Ann Am Thorac Soc 12:1013-1021. https://doi.org/10.1513/AnnalsATS.201412-5690C

32. Walsh SLF, Sverzellati N, Devaraj A et al (2012) Chronic hypersensitivity pneumonitis: High resolution computed tomography patterns and pulmonary function indices as prognostic determinants. Eur Radiol 22:1672-1679. https://doi.org/10.1007/s00330-012-2427-0

33. Wang P, Jones KD, Urisman A et al (2017) Pathologic Findings and Prognosis in a Large Prospective Cohort of Chronic Hypersensitivity Pneumonitis. Chest 152:502-509. https://doi.org/10.1016/j.chest.2017.02.011 
34. Meyer KC (2011) Interstitial lung disease in the elderly: Pathogenesis, diagnosis and management. Sarcoidosis Vasc Diffus Lung Dis 28:3-17

35. Leuschner G, Klotsche J, Kreuter M et al (2020) Idiopathic Pulmonary Fibrosis in Elderly Patients: Analysis of the INSIGHTS-IPF Observational Study. Front Med 7:601279

36. Hanley A, Hubbard RB, Navaratnam V (2011) Mortality trends in asbestosis, extrinsic allergic alveolitis and sarcoidosis in England and Wales. Respir Med 105:1373-1379. https://doi.org/10.1016/j.rmed.2011.05.008

37. Clarson LE, Bajpai $R$, Whittle $R$ et al (2020) Interstitial lung disease is a risk factor for ischaemic heart disease and myocardial infarction. Heart 106:916-922. https://doi.org/10.1136/heartjnl-2019315511

38. Dawod YT, Cook NE, Graham WB et al (2020) Smoking-associated interstitial lung disease: update and review. Expert Rev Respir Med 14:825-834. https://doi.org/10.1080/17476348.2020.1766971

39. Blanchet MR, Israël-Assayag E, Cormier Y (2004) Inhibitory effect of nicotine on experimental hypersensitivity pneumonitis in vivo and in vitro. Am J Respir Crit Care Med 169:903-909. https://doi.org/10.1164/rccm.200210-11540C

40. Cormier Y, Israël-assayag E, Bédard G, Duchaine C (1998) Hypersensitivity pneumonitis in peat moss processing plant workers. Am J Respir Crit Care Med 158:412-417. https://doi.org/10.1164/ajrccm.158.2.9712095

41. Hanak V, Golbin JM, Hartman TE, Ryu JH (2008) High-Resolution CT Findings of Parenchymal Fibrosis Correlate With Prognosis in Hypersensitivity Pneumonitis. Chest 134:133-138. https://doi.org/10.1378/chest.07-3005

42. Sahin H, Brown KK, Curran-Everett D et al (2007) Chronic hypersensitivity pneumonitis: CT features Comparison with pathologic evidence of fibrosis and survival. Radiology 244:591-598. https://doi.org/10.1148/radiol.2442060640

\section{Tables}

Table 1 Characteristics of the included studies in meta-analysis 


\begin{tabular}{|c|c|c|c|c|c|}
\hline $\begin{array}{l}\text { SI Study } \\
\text { no. }\end{array}$ & Year & Country & $\begin{array}{l}\text { Number } \\
\text { of } \\
\text { patients } \\
\text { with HP } \\
\text { (n) }\end{array}$ & $\begin{array}{l}\text { Age } \\
\text { (years) }\end{array}$ & $\begin{array}{l}\text { Gender } \\
(\% \\
\text { men })\end{array}$ \\
\hline
\end{tabular}

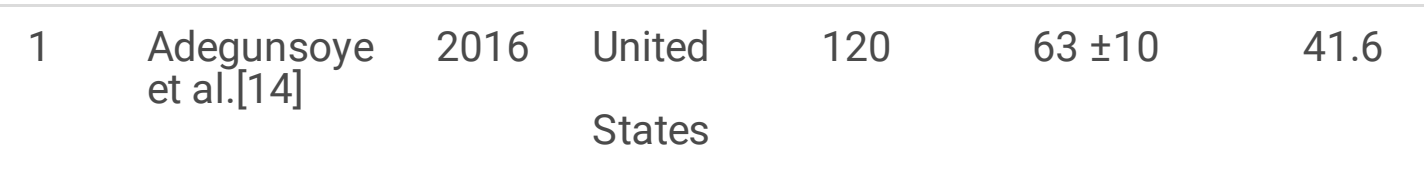

\begin{tabular}{|c|c|c|c|c|c|c|c|}
\hline & & & & & & & $\begin{array}{l}\text { diseases } \\
\text { - Presence of } \\
\text { antibodies to } \\
\text { serum } \\
\text { precipitins }\end{array}$ \\
\hline 2 & $\begin{array}{l}\text { Adegunsoye } \\
\text { et al.[15] }\end{array}$ & 2019 & $\begin{array}{l}\text { United } \\
\text { States }\end{array}$ & 143 & - & - & $\begin{array}{l}\text { - Multidisciplinary } \\
\text { discussion }\end{array}$ \\
\hline
\end{tabular}

$\begin{array}{llllll}\text { Choe et al. } & 2020 & \begin{array}{l}\text { South } \\ \text { Korea }\end{array} & 91 & 59.1 \pm 10.7 & 38.5\end{array}$

- Surgical or transbronchial lung biopsy

- Multidisciplinary discussion

$\begin{array}{lllllll}\begin{array}{l}\text { Chung et al. } 2017 \\ {[17]}\end{array} & \text { United } & 110 & 61 \pm 10 & 48.18 & \begin{array}{l}\text { Multidisciplinary } \\ \text { discussion }\end{array} \\ & & \text { States } & & & & \begin{array}{l}\text { Surgical lung } \\ \text { biopsy }\end{array} \\ & & & & & \\ & & & & \end{array}$

\begin{tabular}{lllllll}
5 & $\begin{array}{l}\text { Chung et al. } \\
\text { [18] }\end{array}$ & 2017 & United & 132 & $62.1 \pm 11.5$ & 39.39 \\
States & & & \\
\hline 6 & $\begin{array}{l}\text { Fernández } \\
\text { Pérez et al. } \\
{[19]}\end{array}$ & 2013 & United & 142 & $58 \pm 12$ & 52.81 \\
\hline
\end{tabular}


(supportive but not required)

- Surgical lung biopsy

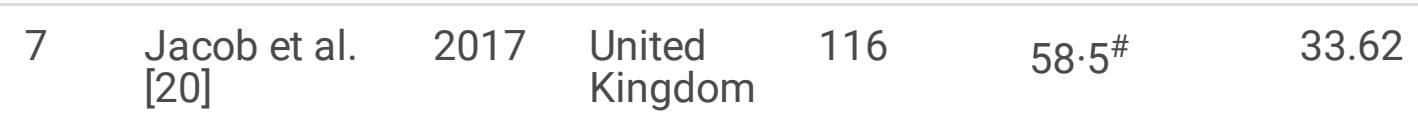

- Multi-disciplinary discussion

\begin{tabular}{lllllll}
8 & $\begin{array}{l}\text { Jacob et al. } \\
{[21]}\end{array}$ & 2017 & $\begin{array}{l}\text { United } \\
\text { Kingdom }\end{array}$ & 98 & $59^{\#}$ & 38.77 \\
\hline 9 & $\begin{array}{l}\text { Jacob et al. } \\
{[22]}\end{array}$ & 2018 & $\begin{array}{l}\text { United } \\
\text { Kingdom }\end{array}$ & 233 & $62^{\#}$ & 39.91
\end{tabular}

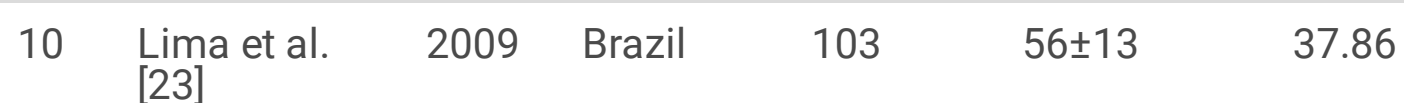

- Re exposure
preceding
respiratory
symptoms
Presence

- Presence of episodic/ persistent respiratory symptoms

- HRCT feature

- Consistent histopathological findings

- No other identifiable cause for the lung disease

Precipitin tests and bronchoscopy were not performed in the majority of cases

11 Long et al. 2016 Germany $72 \quad 57 \pm 2$ [24]

2016 Germany 72

38.88

- Clinical/ HRCT features

- BALF characteristics and/or histopathological findings on biopsy al.[25] 2013 United 177 States
- Consistent clinical history 
and features

suggesting

chronic

respiratory

symptoms

- Abnormal

pulmonary

function tests

- Compatible HRCT features

- Exclusion of other disease that mimics HP

- Biopsy confirmation when a plausible antigen exposure could not be identified

13 Nukui et al. 2019 Japan $63 \quad 62.0 \pm 11.4 \quad 55.55$

[26]

- Clinical, radiological, and histological criteria

$14 \begin{aligned} & \text { Ojanguren } \\ & \text { et al.[27] }\end{aligned} \quad 2018 \quad$ Spain $\quad 160 \quad 60.9 \pm 12.9 \quad 41.87$

- Blood tests (Specific lgG tests for birds and fungi)

- Chest radiography

- HRCT features

- Spirometry

- Static lung volumes, and DLCO

- BALF lymphocytosis and/or transbronchial biopsy or cryobiopsy

- Specific inhalation challenge in some case

$\begin{array}{llllll}15 & \begin{array}{l}\text { Rittig et al. } \\ {[28]}\end{array} \\ {[2019} & \text { Denmark } & 753 & - & 56.70\end{array}$

16 Salisbury et 2019 United

117

$58.3 \pm 11.0$

32.47 al.[29]

States

Presence of at least 2 criteria: 
- Surgical lung biopsy

- Bronchoscopy with BAL lymphocytosis $>20 \%$

- Plausible exposure history

17 Tateishi et 2011 Japan 112 al.[30]

Acute bird-related HP

- History of exposure to avian antigen

- Consistent signs and symptoms of dyspnea, cough, and fever

- Pathologic evidences

- Antibodies and lymphocyte proliferative reactions against bird-related antigen

- Positive provocation test

Chronic bird-related HP

- History of exposure of avian antigen

- Avian antibodies and/or lymphocyte proliferative reactions against bird-related antigen

- Evidence of pulmonary fibrosis with or without granulomas on histopathologic analysis or honeycombing on CT scans;

- Progressive deterioration of pulmonary function 
(duration of one year)

- HP related symptoms (duration of more than 6 months)

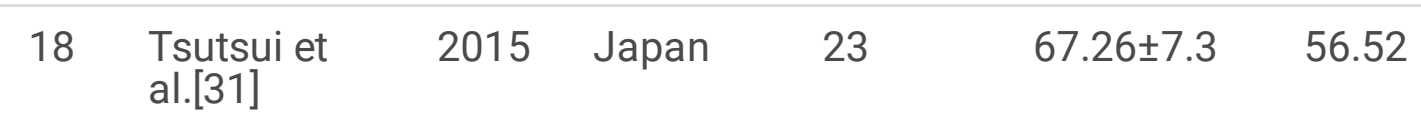

- Inhalation and environmental provocation test

- Immunological examinations

- Exposure of avian antigens

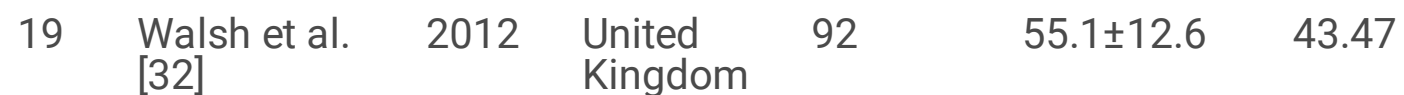

- Multi-disciplinary discussion

\begin{tabular}{|c|c|c|c|c|}
\hline $\begin{array}{ll}20 & \text { Wang et al. } \\
& \text { [33] }\end{array}$ & 2017 & $\begin{array}{l}\text { United } \\
\text { States }\end{array}$ & 119 & 60 \\
\hline
\end{tabular}

- Respiratory symptom or HRCT evidence of DPLD for 4 months or longer duration when no histopathological evidence of fibrosis presence

$\begin{array}{llllll}21 & \text { Wang et al. } 2019 \quad \text { China } 101 & 53.6 \pm 12.4 & 45.54 & \begin{array}{l}\text { The major criteria } \\ \text { include the following } \\ \text { items }\end{array}\end{array}$

- History of symptoms compatible with HP

- Evidence of exposure to the offending antigen in the patient history or through detection by serum or bronchoalveolar lavage (BAL) fluid antibodies

- HRCT features 
- BAL

lymphocytosis (if bronchoscopy was performed)

- histologic changes consistent with HP (if lung biopsy

- Positive natural challenge

The minor criteria are as follows:

- Bibasilar sacs

- Reduced DLco

and

- Arterial hypoxemia, either at rest or with exercise.

The diagnosis was confirmed if 4 of the major criteria and at least 2 of the minor criteria were fulfilled by the subjects

Age data are represented as mean \pm SD unless otherwise stated; \# Median value; HP: Hypersensitivity pneumonitis, DPLD: Diffuse parenchymal lung disease, HRCT: High-resolution computed tomography, BALF: Bronchoalveolar lavage fluid, FVC: Forced vital capacity, DLco: Diffusing capacity for carbon monoxide

\section{Figures}


Records identified through database searching (PubMed, Google scholar, EMBASE and Cochrane library) $(n>1000)$

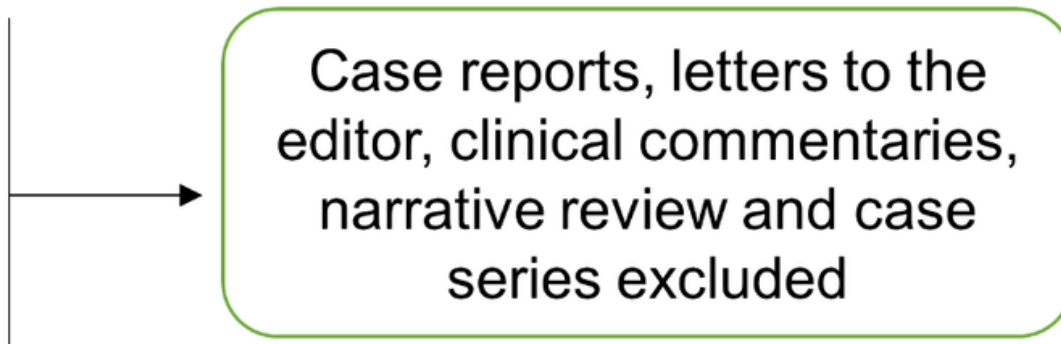

Relevant studies on HP

$(n=24)$

\section{Studies not on HP excluded}

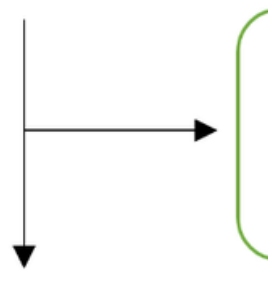

Studies not reporting hazard ratio of the selected parameters excluded $(n=3)$

\section{Studies included in meta-analysis}

$$
(n=21)
$$

Figure 1

Flow diagram of search strategy for selection of articles included in meta-analysis 
(A)

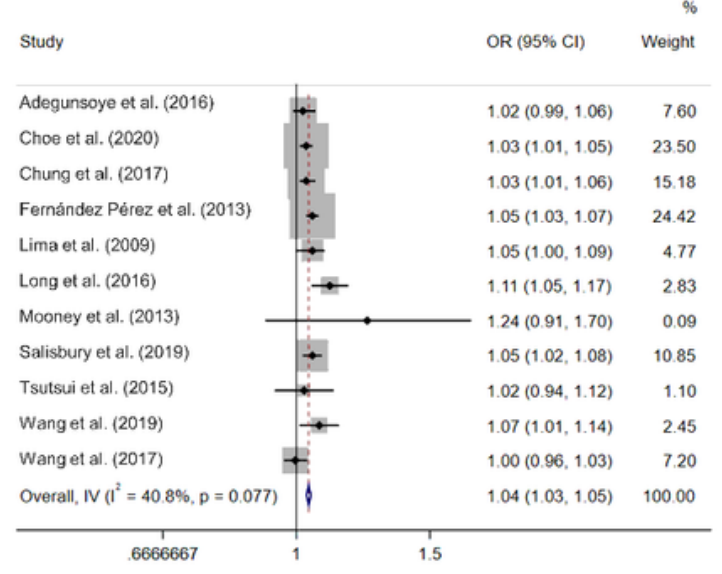

(C)

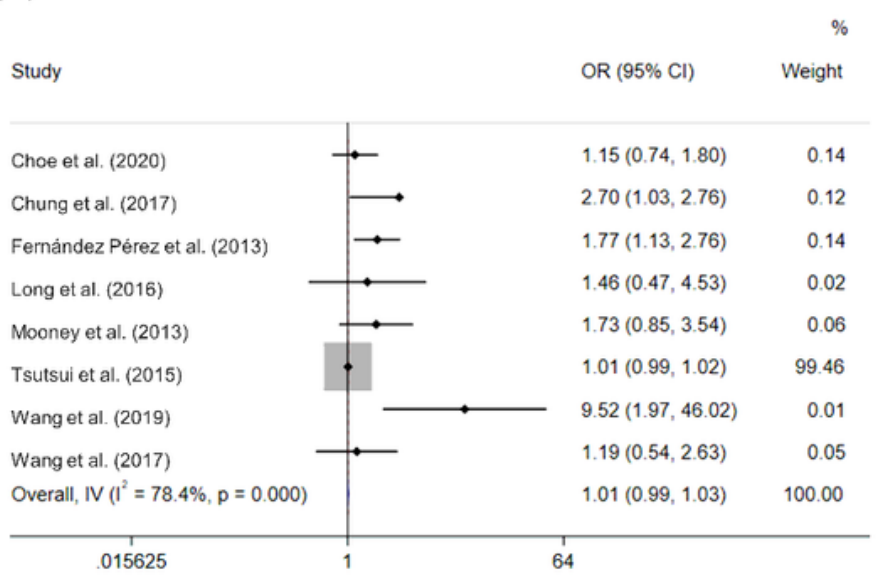

(B)

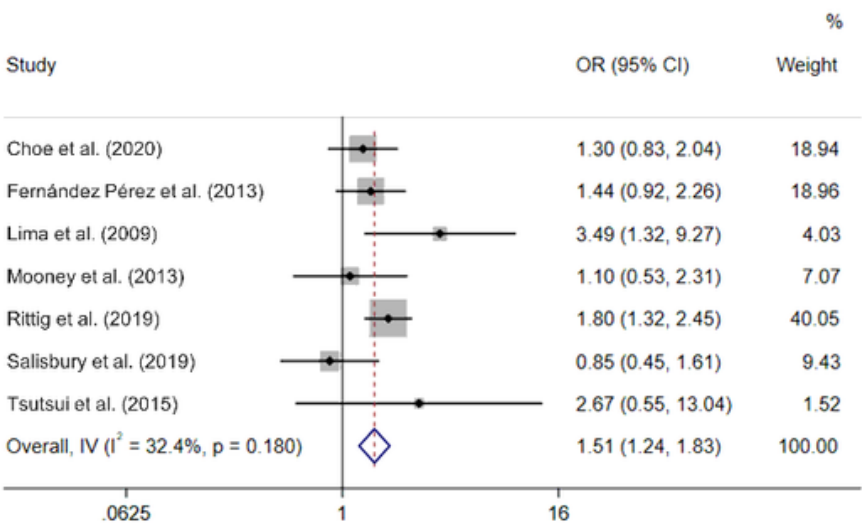

(D)

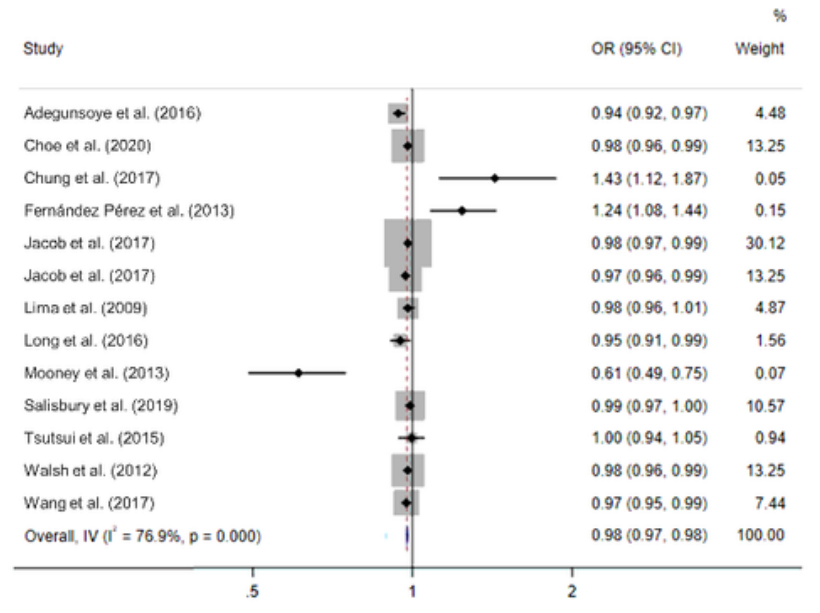

(E)

\begin{tabular}{llr} 
Study & OR $(95 \% \mathrm{Cl})$ & Weight \\
Adegunsoye et al. (2016) & $0.96(0.95,0.98)$ & 17.49 \\
Choe et al. (2020) & $0.99(0.98,1.00)$ & 41.43 \\
Fernández Pérez et al. (2013) & $1.25(1.10,1.42)$ & 0.26 \\
Jacob et al. (2017) & $0.96(0.93,0.98)$ & 6.17 \\
Jacob et al. (2017) & $0.94(0.92,0.96)$ & 9.33 \\
Long et al. (2016) & $0.96(0.92,1.00)$ & 2.38 \\
Mooney et al. (2013) & $0.62(0.50,0.78)$ & 0.09 \\
Salisbury et al. (2019) & $0.99(0.96,1.01)$ & 6.56 \\
Walsh et al. (2012) & $0.96(0.94,0.98)$ & 9.74 \\
Wang et al. (2017) & $0.99(0.96,1.01)$ & 6.56 \\
Overall, IV $\left(I^{2}=85.1 \%, p=0.000\right)$ & $0.97(0.97,0.98)$ & 100.00 \\
\hline
\end{tabular}

Figure 2

Forest plot of univariate data associating mortality risk with (A) age (B) sex (C) smoking history (D) forced vital capacity (FVC) and (E) diffusing capacity for carbon monoxide (DLco) in patients with hypersensitivity pneumonitis (HP) 
(A)

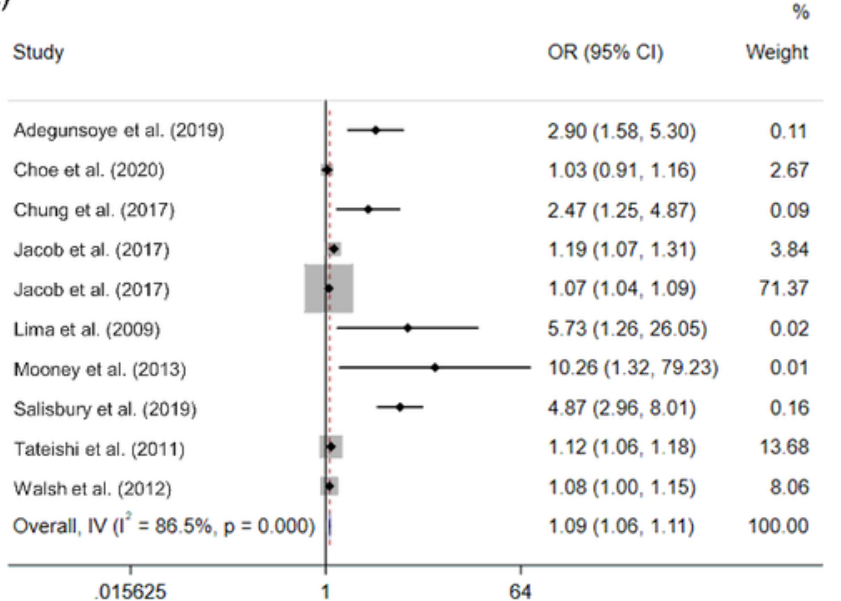

(C)

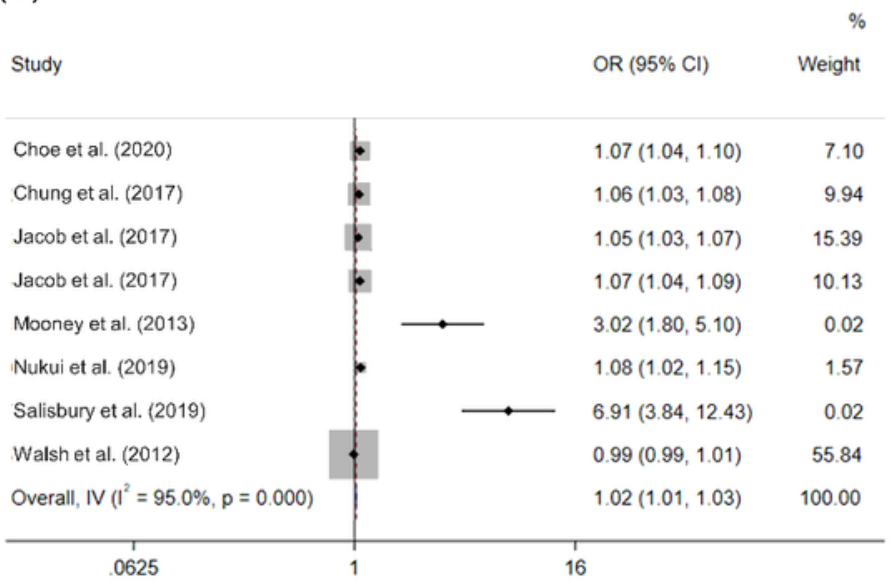

(B)

\begin{tabular}{|c|c|c|}
\hline Study & OR $(95 \% \mathrm{Cl})$ & Weight \\
\hline Choe et al. (2020) & $1.00(0.98,1.02)$ & 58.62 \\
\hline Chung et al. (2017) & $0.15(0.04,0.43)$ & 0.02 \\
\hline Chung et al. (2017) & $0.84(0.43,1.65)$ & 0.05 \\
\hline Jacob et al. (2017) & $1.04(1.02,1.07)$ & 40.97 \\
\hline Lima et al. (2009) & $0.26(0.07,0.90)$ & 0.01 \\
\hline Mooney et al. (2013) & $1.40(0.73,2.71)$ & 0.05 \\
\hline Salisbury et al. (2019) & $1.04(0.78,1.40)$ & 0.27 \\
\hline Overall, IV $\left(I^{2}=72.3 \%, p=0.001\right)$ & $1.02(1.00,1.03)$ & 100.00 \\
\hline .03125 & & \\
\hline
\end{tabular}

(D)

Study $\quad$ OR $(95 \% \mathrm{Cl})$

\begin{tabular}{|c|c|c|}
\hline Chung et al. (2017) & $0.41(0.17,0.99)$ & 0.01 \\
\hline Choe et al. (2020) & $0.98(0.97,1.00)$ & 22.45 \\
\hline Chung et al. (2017) & $0.31(0.12,0.79)$ & 0.01 \\
\hline Jacob et al. (2017) & $0.98(0.97,1.00)$ & 22.45 \\
\hline Lima et al. (2009) & $1.66(0.58,4.71)$ & 0.00 \\
\hline Mooney et al. (2013) & $0.91(0.51,1.64)$ & 0.02 \\
\hline Nukui et al. (2019) & $1.30(0.74,2.27)$ & 0.02 \\
\hline Salisbury et al. (2019) & $0.81(0.64,1.05)$ & 0.08 \\
\hline Tateishi et al. (2011) & $0.96(0.93,1.00)$ & 3.95 \\
\hline Walsh et al. (2012) & $1.00(0.98,1.00)$ & 51.02 \\
\hline Overall, IV $\left(I^{2}=62.5 \%, p=0.004\right)$ & $0.99(0.98,1.00)$ & 100.00 \\
\hline .125 & & \\
\hline
\end{tabular}

(E)

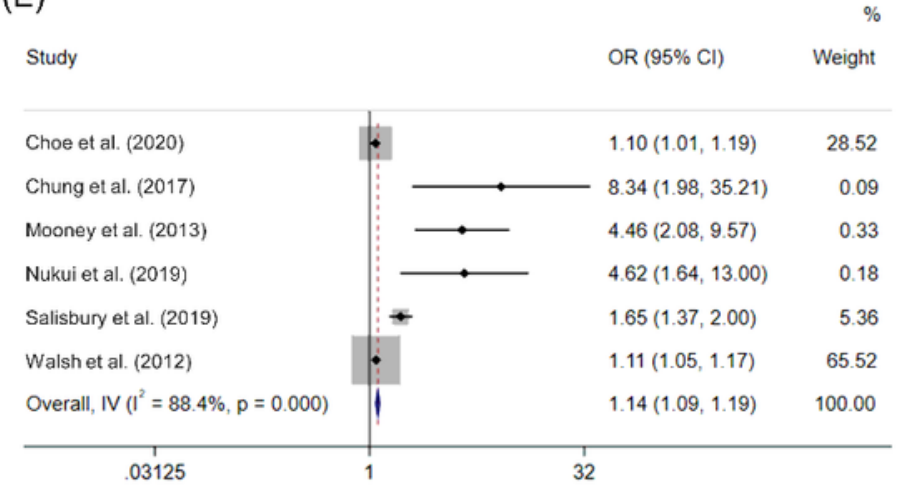

\section{Figure 3}

Forest plot of univariate data associating mortality risk with (A) honeycombing (B) mosaic attenuation (C) reticulation (D) ground glass opacity (GGO) and (E) traction bronchiectasis in patients with hypersensitivity pneumonitis (HP) 
(A)

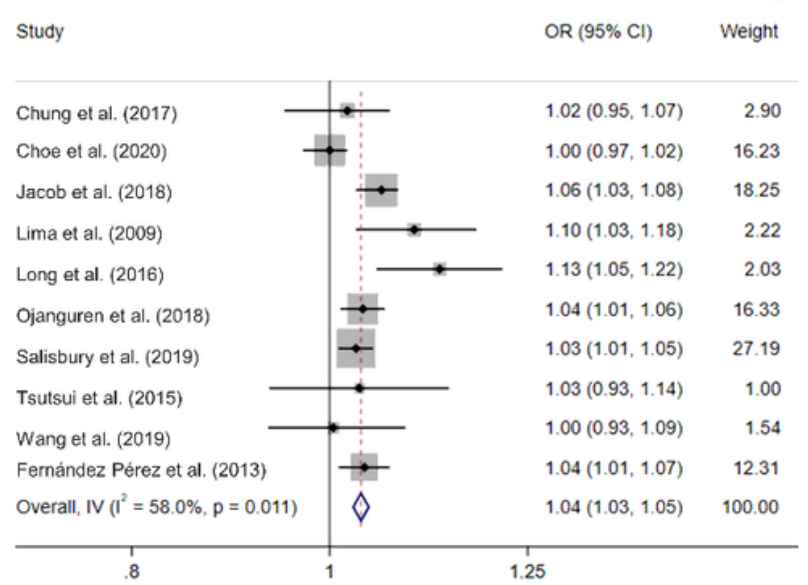

(B)

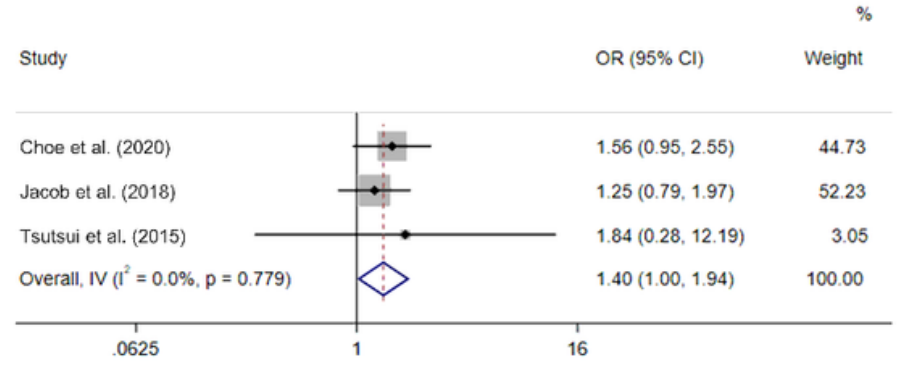

(D)

$\%$ Study $\quad$ OR $(95 \% \mathrm{Cl})$ Weight

Weight

Chung et al. (2017)

Choe et al. (2020)

Fernández Pérez et al. (2013)

Long et al. (2016)

Mooney et al. (2013)

Salisbury et al. (2019)

Tsutsui et al. (2015)

Overall, IV $\left(I^{2}=68.4 \%, p=0.004\right)$
$1.08(0.80,1.47) \quad 0.08$

$0.98(0.96,0.99) \quad 29.52$

$1.36(1.10,1.68) \quad 0.16$

$0.94(0.90,0.99) \quad 3.15$

$0.70(0.55,0.92) \quad 0.11$

$0.97(0.96,0.98) \quad 65.74$

$0.97(0.90,1.05) \quad 1.26$

$0.97(0.96,0.98) \quad 100.00$
Overall, IV $\left(I^{2}=74.5 \%, p=0.001\right)$

.03125

(E)

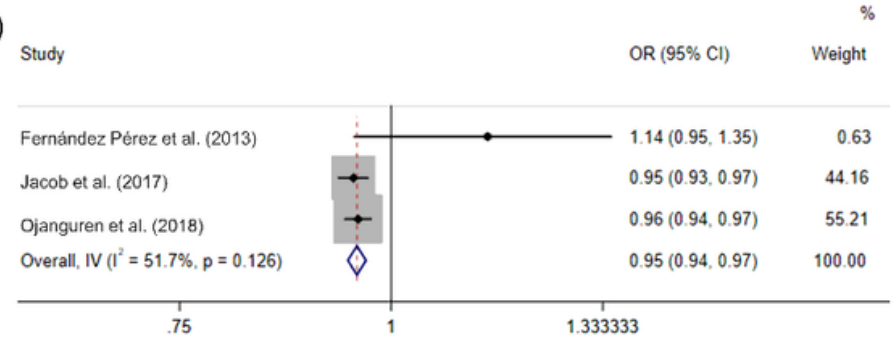

\section{Figure 4}

Forest plot of multivariate data associating mortality risk with (A) age (B) sex (C) smoking history (D) forced vital capacity (FVC) and (E) diffusing capacity for carbon monoxide (DLCO) in patients with hypersensitivity pneumonitis (HP) 
(A)

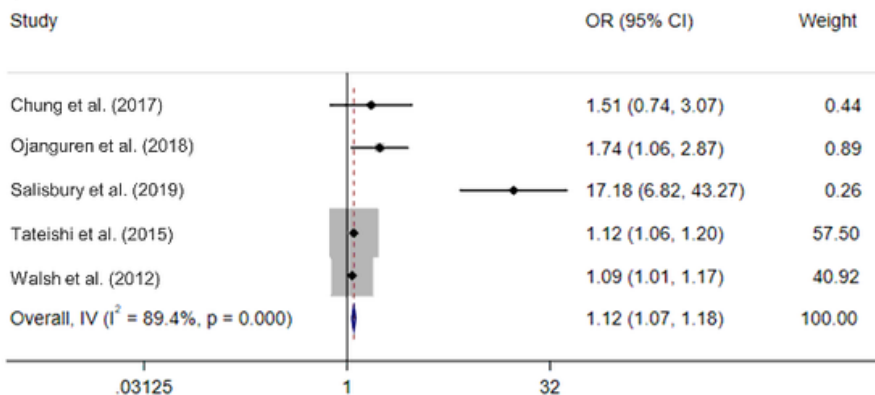

(C)

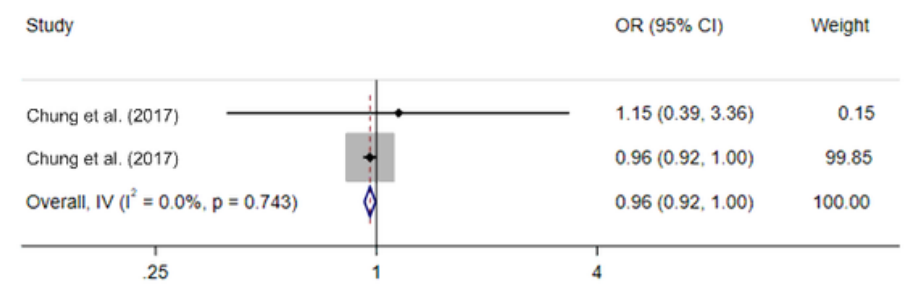

(B)

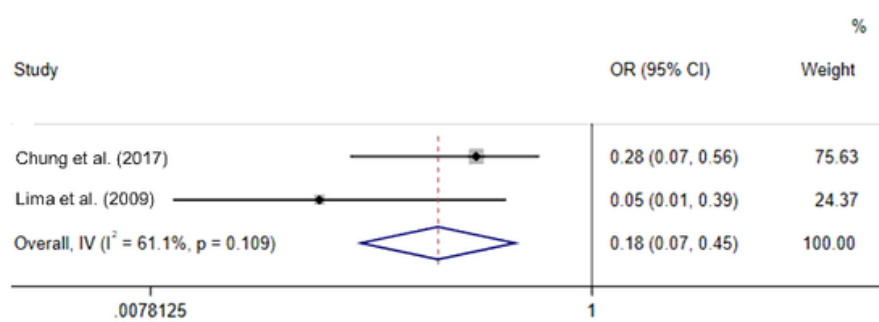

(D) Study $_{\text {to }}$

OR $(95 \% \mathrm{Cl}) \quad$ Weight

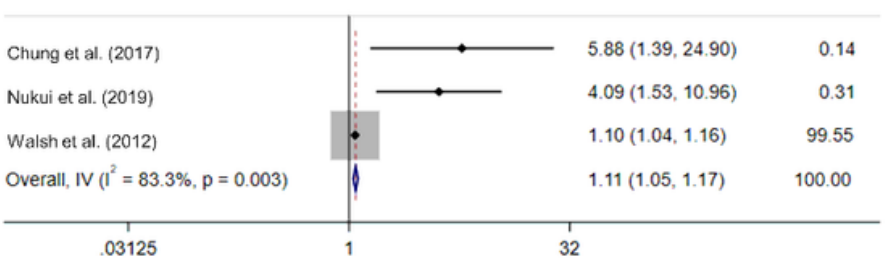

\section{Figure 5}

Forest plot of multivariate data associating mortality risk with $(A)$ honeycombing $(B)$ mosaic attenuation (C) ground glass opacity (GGO) and (D) traction bronchiectasis in patients with hypersensitivity pneumonitis (HP)

\section{Supplementary Files}

This is a list of supplementary files associated with this preprint. Click to download.

- Supplementary.docx 